The Israeli Journal of Aquaculture - Bamidgeh, IJA_73.2021.1233796, 7 pages

CCBY-NC-ND-4.0 • https://doi.org/10.46989/001c.21231

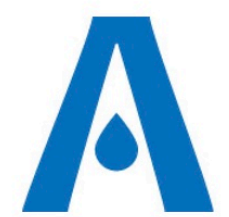

The IJA is a peer-reviewed open-access, electronic journal, freely available without charge to users

Produced by the AquacultureHub non-profit Foundation Sale of IJA papers is strictly forbidden

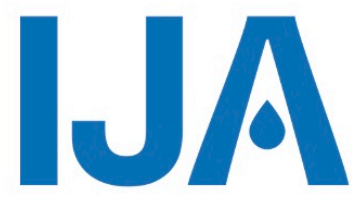

\title{
Effects of salinity, pH and alkalinity on hatching rate of fertilized eggs of Penaeus monodon
}

\author{
Song Jianga,c, Qing-Xia Liua, Wen-Chuan Zhoub, Qiu-Long Zhao ${ }^{b}$, \\ Fa-Lin Zhoua,c, Qi-Bin Yanga,c Jian-Hua Huanga,c, Li-Shi Yanga,c, \\ Yun-Dong Lia, ${ }^{a}$, Shi-Gui Jiang ${ }^{a *}$
}

a Guangdong Provincial Key Laboratory of Fishery Ecology and Environment; South China Sea Fisheries Research Institute, Chinese Academy of Fisheries Sciences, Guangzhou 510300, P.R. China

${ }^{b}$ Shenzhen Fisheries Service Center and Aquatic Product Technology promotion station, Shenzhen 518067, P.R. China

c Shenzhen Base of South China Sea Fisheries Research Institute, Chinese Academy of Fishery Sciences, Shenzhen 518108, P.R. China

Key words: Penaeus monodon, Fertilized egg, Hatching rate, Salinity, pH, Alkalinity

\begin{abstract}
The fertilized eggs of "Nanhai 2" Penaeus monodon bred by our research group were incubated at the same temperature $\left(30^{\circ} \mathrm{C}\right)$, different salinity $(20,25,30$, $35,40)$, different $\mathrm{pH}(7.0,7.5,8.0,8.5,9.0)$ and different alkalinity $(2.0$ $\mathrm{mmol} / \mathrm{L}, 2.5 \mathrm{mmol} / \mathrm{L}, 3.0 \mathrm{mmol} / \mathrm{L}, 3.5 \mathrm{mmol} / \mathrm{L}, 4.0 \mathrm{mmol} / \mathrm{L}$ ) to explore the effects of salinity, $\mathrm{pH}$ and alkalinity on hatching rate of fertilized eggs of $P$. monodon. The results showed that the hatching rate of fertilization rate of $P$. monodon was closely related to salinity, and the best hatching rate was obtained when the seawater salinity was 30 with the average hatching rate was $82.60 \%$. The hatching rate was very low when the salinity was as low as 20 or as high as 40, which was significantly lower than that of other treatments $(P<0.05)$. The hatching effect of the fertilized eggs of $P$. monodon was closely related to the $\mathrm{pH}$ value of seawater, and the slightly alkaline seawater was conducive to the normal development of the fertilized eggs. Among them, the hatching effect of the seawater $\mathrm{pH}$ value of 8.0 was the best, and the average hatching rate of the fertilized eggs was $80.62 \%$. Too low or too high pH value of the seawater was not conducive to the development of the embryo, and the hatching rate of the fertilized eggs decreased in varying degrees. There was no significant correlation between the hatching effect of fertilized eggs and the change of seawater alkalinity. The average hatching rate of fertilized eggs ranged from $78.65 \%$ to $83.12 \%$ in the alkalinity range of $2.0-4.0 \mathrm{mmol} / \mathrm{L}$.
\end{abstract}

* Corresponding author. Shi-gui Jiang, e-mail: jiangsg@21.com 


\section{Introduction}

The black tiger shrimp (Penaeus monodon, Crustacea, Decapoda, Penaeidae) is the most widely farmed species in the world and the species of choice for many farmers due to its rapid growth rate, low-cost food requirements and ability to reach a larger size than other commonly farmed species (Song et al., 2018; Song et al., 2019; Kenway et al. 2006). However, in recent years, due to the eutrophication of coastal areas and the decline of sea water quality, shrimp breeding in Guangdong, Guangxi, Hainan and other provinces in China has encountered common problems, and there are many diseases in the breeding processes, which are difficult to control(Lin et al., 2019). In particular, the acidification of sea water which cause the egg membrane to soften and lose their elasticity, and enables the embryo easily to break the membrane and die (Liang et al., 1999). In the artificial propagation of $P$. monodon, low hatching rate, abnormal embryo development and larval slime disease often occur, these seriously affect the quality, yield and management efficiency of the shrimp hatching farms (John et al., 1992; Anand et al., 2019; Primavera et al. 1981). Wongprasert et al. used the artificially cultured mature $P$. monodon, when they studied the embryonic development of $P$. monodon and the effects of temperature and salinity on embryonic development and process from egg production, during which the hatching of larvae was observed and described. The results showed that under the condition of water temperature of $29.5 \mathrm{C}^{\circ}$ and salinity of 28 , the whole embryonic development process took about 12 hours (Wongprasert et al., 2006). Different water temperature and salinity led to significant effects on the hatching time and fertilization rate of fertilized eggs. The experimental water temperature decreased from $29.5 \mathrm{C}^{\circ}$ to $26.8 \mathrm{C}^{\circ}$, and the incubation time increased from $11.3 \mathrm{~h}$ to $15 \mathrm{~h}$. The optimal incubation temperature was $28 \mathrm{C}^{\circ}-30 \mathrm{C}^{\circ}$, and the optimum salinity was $27.93-33.01$. When the salinity was lowered than 22 or increased higher than 38, the fertilized eggs could not develop normally (Primavera et al., 1981). However, the effects of $\mathrm{pH}$ and alkalinity on the development of fertilized eggs of artificial breeding of $P$. monodon have not been reported yet.

It is of great significance for the development of $P$. monodon artificial breeding and aquaculture industry to find out the optimal range of environmental factors for the hatching of fertilized eggs. In this study, seawater with different salinity, $\mathrm{pH}$ and alkalinity gradients were set up to carry out the incubation experiment of artificial breeding of $P$. monodon. By observing and comparing the hatching effect of each experimental group, the optimal salinity, $\mathrm{pH}$ value and alkalinity of the fertilized eggs of $P$. monodon were explored, so as to provide reference for improving the production efficiency of artificial breeding of $P$. monodon.

\section{Experimental materials}

\section{Materials and Methods}

The experiment was conducted in Shenzhen Base of South China Sea Fisheries Research Institute, Chinese Academy of Fisheries Sciences in April, 2020. The fertilized eggs were obtained from the broodstock shrimp "Nanhai 2" which were cultured by our research group. The reagents used in the experiment were sodium chloride, hydrochloric acid (analytical purity), industrial sodium hydroxide $[\mathrm{NaOH}]$, industrial sodium bicarbonate $\left[\mathrm{Na}_{2} \mathrm{HCO}_{3}\right]$, potassium hydrogen phthalate $\left[\mathrm{C}_{8} \mathrm{H}_{5} \mathrm{KO}_{4}\right]$ standard buffer solution $\left(\mathrm{pH}=6.86,25^{\circ} \mathrm{C}\right)$, mixed indicator of methyl red and methylene blue (The reagents above were purchased from Guangdong Ruibo Biotechnology Co., Ltd.). The sea water used in the experiment was natural seawater, which was used for standby after disinfection, sedimentation and filtration. The instruments used in the experiment were analytical balance (la230s, sartorius), pHs-3c type pH meter, thermometer, salinity meter, 10 plastic buckets of $30 \mathrm{~L}$, air pump and aerator. 


\section{Experimental methods}

Effects of different salinity on hatching rate of fertilized eggs of $P$. monodon

The hatching effect of fertilized eggs under different salinity conditions was observed and compared under the condition of constant incubation water temperature $\left(30{ }^{\circ} \mathrm{C}\right)$ and $\mathrm{pH}$ value. Five salinity gradients and three replicates were set for each gradient. The volume of the experimental bucket was $30 \mathrm{~L}$, and each bucket was filled with $20 \mathrm{~L}$ seawater. The salinity of the incubation bucket was adjusted to $20,25,30,35$ and 40 by adding sodium chloride or fresh water. High salinity seawater was calculated by the formula $\mathrm{V} x=\mathrm{V}_{1}(\mathrm{~S} 1-\mathrm{S} 2) / \mathrm{S} 2$

where $V_{x}$ was cubic number of freshwater to be added, $V_{1}$ was the volume of raw seawater, S1 and S2 were original seawater salinity and adjusted salinity respectively.

While low salinity seawater was calculated by adding 1 degree of salinity per cubic meter of water and adding $1 \mathrm{~kg}$ of sodium chloride. In each incubator, the gas was slightly inflated continuously. About 1500 newly produced fertilized eggs were put into each incubator. After hatching for 18 hours, the nauplii of each hatching bucket was counted to establish the hatching rate of fertilized eggs.

\section{Effects of different $\mathrm{pH}$ values on hatching rate of fertilized eggs of $\mathrm{P}$. monodon}

The hatching effect of fertilized eggs under different $\mathrm{pH}$ values was observed and compared under constant water temperature $\left(30^{\circ} \mathrm{C}\right)$. The salinity was measured with the same used in the first experiment. Five $\mathrm{pH}$ gradients and three replicates were set for each gradient. The $\mathrm{pH}$ value of each incubation bucket was adjusted to 7.0, 7.5, 8.0, 8.5 and 9.0 respectively with hydrochloric acid or sodium hydroxide. In each incubator, the gas was slightly inflated continuously. About 1500 fertilized eggs were put into each incubator. After hatching for 18 hours, the nauplii of each hatching bucket was counted to calculate the hatching rate of fertilized eggs.

\section{Effects of different alkalinity on hatching rate of fertilized eggs of $P$. monodon}

The fertilized eggs of $P$. monodon were incubated in seawater with different alkalinity rates under incubation temperature $\left(30^{\circ} \mathrm{C}\right.$ ) and salinity (the optimum salinity of Experiment 1). Five alkalinity gradients and three replicates were set for each gradient. Sodium carbonate was used to increase the alkalinity of seawater in each incubator by $0 \%, 25 \%$, $50 \%, 75 \%$ and $100 \%$ respectively. One air stone was placed in each hatching bucket, and continuous weak aeration was conducted to increase oxygen. About 1500 newly born fertilized eggs were put into each incubator. After hatching for 18 hours, the nauplii of each hatching bucket was counted to calculate the hatching rate of fertilized eggs.

\section{Results}

Effects of different salinity on hatching rate of fertilized eggs of $P$. monodon

The hatching effect of fertilized eggs of $P$. monodon in different salinity concentration of the seawater was shown in Table $\mathbf{1}$.

Table 1 Effects of different salinity on hatching rate of fertilized eggs of Penaeus monodon

\begin{tabular}{|c|c|c|c|c|c|c|c|}
\hline \multirow[b]{2}{*}{ Temperature } & \multirow[b]{2}{*}{$\mathrm{pH}$} & \multirow[b]{2}{*}{ Salinity } & \multicolumn{3}{|c|}{ Hatchability/\% } & \multirow{2}{*}{$\begin{array}{l}\text { Coefficient } \\
\text { of variation }\end{array}$} & \multirow{2}{*}{$\begin{array}{c}\text { Average } \\
\text { hatching } \\
\text { rate/\% }\end{array}$} \\
\hline & & & Repeat 1 & Repeat 2 & Repeat 3 & & \\
\hline 30 & 8.0 & 20 & 11.02 & 13.95 & 13.58 & 12.42 & $12.85^{d}$ \\
\hline 30 & 8.0 & 25 & 77.15 & 71.51 & 71.96 & 4.26 & $73.54^{b}$ \\
\hline 30 & 8.0 & 30 & 86.66 & 80.11 & 81.08 & 4.28 & $82.60^{a}$ \\
\hline 30 & 8.0 & 35 & 50.35 & 45.29 & 50.18 & 5.91 & $48.61^{c}$ \\
\hline 30 & 8.0 & 40 & 4.96 & 7.81 & 7.82 & 24.02 & $6.86^{d}$ \\
\hline
\end{tabular}


The hatching rate of fertilization rate of $P$. monodon was closely related to salinity. When the salinity was too low or too high, it affected the embryonic development of fertilized eggs. Among the five salinity gradients, salinity 30 PPT got the best hatching rate, with an average of $82.60 \%$, followed by 25 PPT, with an average hatching rate of $63.54 \%$; when the salinity was 35 PPT, the hatching rate of fertilized eggs was only $48.61 \%$ and when it dropped to 20 PPT and increased to 40 PPT, the hatching rate of all the fertilized eggs were significantly lower.

Effects of different $\mathrm{pH}$ values on hatching rate of fertilized eggs of $P$. monodon

The hatching effects of the fertilized eggs of $P$. monodon in different $\mathrm{pH}$ values were shown in Table 2.

Table 2 Effects of different $\mathrm{pH}$ values on hatching rate of fertilized eggs of Penaeus monodon

\begin{tabular}{|c|c|c|c|c|c|c|c|}
\hline \multirow[b]{2}{*}{ Temperature } & \multirow[b]{2}{*}{$\mathrm{pH}$} & \multirow[b]{2}{*}{ Salinity } & \multicolumn{3}{|c|}{ Hatchability/\% } & \multirow{2}{*}{$\begin{array}{l}\text { Coefficient } \\
\text { of variation }\end{array}$} & \multirow{2}{*}{$\begin{array}{c}\text { Average } \\
\text { hatching } \\
\text { rate/\% }\end{array}$} \\
\hline & & & Repeat 1 & Repeat 2 & Repeat 3 & & \\
\hline 30 & 7.0 & 30 & 70.24 & 64.08 & 64.62 & 5.14 & $66.31^{\mathrm{c}}$ \\
\hline 30 & 7.5 & 30 & 76.14 & 73.55 & 72.84 & 2.34 & $74.18^{b}$ \\
\hline 30 & 8.0 & 30 & 78.24 & 83.11 & 80.51 & 3.02 & $80.62^{a}$ \\
\hline 30 & 8.5 & 30 & 78.20 & 76.94 & 73.69 & 3.05 & $76.28^{\mathrm{ab}}$ \\
\hline 30 & 9.0 & 30 & 62.07 & 63.27 & 61.09 & 1.76 & $62.14^{c}$ \\
\hline
\end{tabular}

The data in Table 2 shows that: under the conditions of incubation temperature of $30^{\circ} \mathrm{C}$ and salinity of $30^{\circ} \mathrm{C}$, the hatching effect of fertilized eggs of $P$. monodon was closely related to the $\mathrm{pH}$ value of seawater. The slightly alkaline seawater was conducive to the normal development of fertilized eggs, and the hatching rate was higher. Too low or too high $\mathrm{pH}$ value of seawater negatively affected the development of the embryos, and the hatching rate of fertilized eggs decreased in different degrees. The results showed that the hatching rate of fertilized eggs was $80.62 \%$ at $\mathrm{pH} 8.0,76.28 \%$ at $\mathrm{pH} 8.5,62.14 \%$ at 9.0 , and $66.31 \%$ at 7.0 .

Effects of different alkalinity on hatching rate of fertilized eggs of $P$. monodon

The hatching effect of fertilized eggs of $P$. monodon in different alkalinity seawater was shown in Table 3.

Table 3 Effects of different alkalinity on hatching rate of fertilized eggs of Penaeus monodon

\begin{tabular}{|c|c|c|c|c|c|c|c|}
\hline \multirow{2}{*}{ Temperature } & \multirow{2}{*}{ Salinity } & \multirow{2}{*}{$\begin{array}{l}\text { Alkalinity } \\
\text { (mmol /L) }\end{array}$} & \multicolumn{3}{|c|}{ Hatchability/\% } & \multirow{2}{*}{$\begin{array}{l}\text { Coefficient } \\
\text { of variation }\end{array}$} & \multirow{2}{*}{$\begin{array}{c}\text { Average } \\
\text { hatching } \\
\text { rate/\% }\end{array}$} \\
\hline & & & Repeat 1 & Repeat 2 & Repeat 3 & & \\
\hline 30 & 30 & 2.0 & 80.56 & 83.49 & 83.17 & 1.95 & $82.41^{a}$ \\
\hline 30 & 30 & 2.5 & 84.31 & 82.73 & 82.31 & 1.27 & $83.12^{\mathrm{a}}$ \\
\hline 30 & 30 & 3.0 & 84.51 & 80.52 & 82.06 & 2.44 & $82.36^{a}$ \\
\hline 30 & 30 & 3.5 & 80.69 & 81.44 & 78.36 & 2.00 & $80.16^{a}$ \\
\hline 30 & 30 & 4.0 & 80.25 & 77.89 & 77.82 & 1.76 & $78.65^{a}$ \\
\hline
\end{tabular}

It can be seen from the experimental results in Table 3 that there was no significant correlation between the hatching effect of fertilized eggs of $P$. monodon and the change of seawater alkalinity under the conditions of incubation seawater temperature of $30^{\circ} \mathrm{C}$ and salinity of $30^{\circ} \mathrm{C}$. In the alkalinity range of $2.0-4.0 \mathrm{mmol} / \mathrm{l}$, the change of alkalinity had no significant impact on the development of fertilized eggs, and the average hatching rate of 
fertilized eggs ranged from $78.65 \%$ to $83.12 \%$ and there were no significant difference among the three groups.

\section{Discussion}

Effect of salinity on hatching rate of fertilized eggs of $P$. monodon

The development of fertilized eggs of $P$. monodon was affected by osmotic pressure, and the osmotic pressure regulation of $P$. monodon embryos was directly affected by salinity (Liang et al., 1999). The osmotic pressure of fertilized eggs could be maintained at a relatively stable level through self-regulation within the suitable salt range (Xue et al., 2012). In this experiment, the results showed that the change of salinity had a great influence on the hatching rate of fertilized eggs of $P$. monodon. When the salinity was as low as 20 PPT or as high as 40 PPT, the fertilized eggs were not able to develop normally. The main reason was that the change of seawater salinity reflects the difference of inorganic ion content in water body, and the latter would change the osmotic pressure of seawater. Any kind of aquatic organisms had a certain range of adaptation to osmotic pressure, beyond which the normal physiological metabolism of organisms will affected survival (Neuparth et al., 2002). In the range of suitable salinity, each species had a certain ability to regulate osmotic pressure, which was a physiological process that consumes energy (Zhou et al., 2020). Although the adult shrimps of $P$. monodon was able to adapt to a wide range of salinity and be cultured in waters with salinity of 2-40 (Jiang et al., 2018), and the results of this experiment showed that the requirements of salinity for the embryonic development of fertilized eggs were stricter. In order to improve the hatching rate in production, the salinity should be about 30 PPT.

\section{Effect of $\mathrm{pH}$ value on hatching rate of fertilized eggs of $P$. monodon}

In the development of fertilized eggs of $P$. monodon, the $\mathrm{pH}$ value of hatching water was a very important factor ( $\mathrm{Md}$ et al., 2005). In the water with low or high $\mathrm{pH}$, the fertilized eggs died due to the corrosion of the epidermal cells and the incomplete development of the ion regulation mechanism (Noor-Hamid et al., 1994). In this experiment, the results showed that the hatching rate of fertilized eggs of $P$. monodon was $80.62 \%$ at $\mathrm{pH} 8.0$, but the average hatching rate of fertilized eggs was $40.31 \%$ and $54.12 \%$ respectively when $\mathrm{pH}$ value was 7.0 and 9.0 . The reason for this phenomenon might be that the cell membrane of the fertilized eggs had limited regulation ability. The change of $\mathrm{pH}$ value in a certain range would not affect the normal development of the embryo, but once the change exceeded a certain range, it would affect the balance of the internal environment of the embryo, and then caused damage to it. For example, if the $\mathrm{pH}$ value was too low, the fertilized egg membrane would soften and lost its elasticity, and the embryo was easy to break the membrane and die; if the $\mathrm{pH}$ value was too high, the egg membrane would dissolve earlier and the embryo would die in the midway. Therefore, the $\mathrm{pH}$ value of incubation water should be kept around 8.0 in seedling production.

\section{Effect of alkalinity on hatching rate of fertilized eggs of $P$. monodon}

Carbonate and other alkaline substances were able to complicate with heavy metal ions in water, and even form precipitation, which reduced the concentration of free metal ions in water, thus reducing the toxicity of heavy metals (Gopalakrishnan et al., 2011). Alkalinity also adjusted the relationship between $\mathrm{CO}_{2}$ production and consumption and stabilize the $\mathrm{pH}$ value of water (Zhang et al., 2011; Zhan et al., 2013). Therefore, in the water where the fertilized eggs of $P$. monodon hatch, keeping proper alkalinity was conducive to the normal development of the fertilized eggs. In the range of 2.0-4.0 $\mathrm{mmol} / \mathrm{L}$, alkalinity had no toxic effect on the development of fertilized eggs of $P$. monodon. The hatching rate of fertilized eggs ranged from $78.65 \%$ to $83.12 \%$. Analysis of variance showed that there was no significant difference in the hatchability of fertilized eggs in the range of alkalinity $2.0-4.0 \mathrm{mmol} / \mathrm{L}$, which showed that the above concentrations were within the safe concentration range.

\section{Acknowledgements}

The Israeli Journal of Aquaculture - Bamidgeh • IJA.73.2021.1238275 
This study was supported by Fund of Guangdong Provincial Key Laboratory of Fishery Ecology and Environment (FEEL-2020-6), Performance projects: aquaculture technology research (2130106), Central Public-interest Scientific Institution Basal Research Fund, CAFS (2020TD30), Financial Fund of Ministry of Agriculture and Rural affairs of China (NHYYSWZZZYKZX2020), Industrial Technology System of Modern Agriculture (CARS-48), Guangdong Provincial Special Fund For Modern Agriculture Industry Technology Innovation Teams (No. 2019KJ149).

\section{References}

Anand P.S.S., Balasubramanian C.P., Francis B., Panigrahi A., Vijayan K.K., 2019. Reproductive performance of wild brooders of indian white shrimp, Penaeus indicus: potential and challenges for selective breeding program. Journal of Coastal Research., 86(sp1):65.

Gopalakrishnan A., Rajkumar M., Sun J., Martin G.G., Parida A., 2011. Impact of mineral deposition on shrimp, Penaeus monodon in a high alkaline water. Journal of Environmental Biology., 32(3):283.

Jiang S., Zhou F.L., Huang J.H., Yang Q.B., Yang L.S. and Jiang S.G., 2018. Effects of eyestalk ablation on feeding, gonad development and energy conversion of Penaeus monodon broodstock. Pakistan J. Zool., 50:1217-1223.

http://dx.doi.org/10.17582/journal.pjz/2018.50.4.1217.1223

Jiang S., Zhou F.L., Yang Q.B., Hang J.H., Yang L.S., Jiang S.G., 2019. Impact of temperature stress on oxygen and energy metabolism in the hepatopancreas of the black tiger shrimp (Penaeus monodon, Crustacea, Decapoda, Penaeidae). Pakistan Journal of Zoology., 51:141-148.

John T.O., Kathy B., Jeffrey M., 1992. Effects of Salinity on Survival and Growth of Postlarval Penaeus vannamei. Gulf \& Caribbean Research., 8:12-18. http://dx.doi.org/10.18785/grr.0804.07

Kenway M., Macbeth M., Salmon M., Mcphee C., Benzie J., Wilson K., Knibb W., 2006. Heritability and genetic correlations of growth and survival in black tiger prawn Penaeus monodon reared in tanks. Aquaculture., 259(1-4):138-145. https://doi.org/10.1016/j.aquaculture.2006.05.042

Liang H. F., Wei S. G., 1999. Effects of different sea water densities on embryonic development and nauplius metamorphosis of Penaeus monodon. 19(2):69-72.

Lin., Shin-Jen., Chen., Yi-Fan., Hsu., Kai-Cheng., Yun-Ling., Ko., Tzu-Ping., Lo.,Chu-Fang., Wang., Han-Ching., Hao-Ching., 2019. Structural insights to the heterotetrameric interaction between the vibrio parahaemolyticus piravp and pirBvp toxins and activation of the cry-like pore-forming domain. Toxins.

Md K., Rahman M.M., Bapary M.A.J., Lubna Y., Md N., 2005. Influence of ph on the atpase activity and solubility of Macrobrachium rosenbergii and Penaeus monodon muscle myofibrillar protein. Pakistan Journal of Biological sciences. 8(7):982-988.

Neuparth T., Costa F. O., Costa M. H., 2002. Effects of temperature and salinity on life history of the marine amphipod Gammarus locusta. Implications for Ecotoxicological testing. Ecotoxicology., 11(1):61-73.

Noor-Hamid S., Fortes R.D., Parado-Estepa F., 1994. Effect of pH and ammonia on survival and growth of the early larval stages of Penaeus monodon fabricius. Aquaculture., 125(1-2):67-72. https://doi.org/10.1016/0044-8486(94)90283-6 Primavera J.H., Posadas R.A., 1981. Studies on the egg quality of Penaeus monodon fabricius, based on morphology and hatching rates. Aquaculture., 22(3):269-277. https://doi.org/10.1016/0044-8486(81)90152-6

Wongprasert K., Asuvapongpatana S., Poltana P., Tiensuwan M., Withyachumnarnkul B., 2006. Serotonin stimulates ovarian maturation and spawning in the black tiger shrimp penaeus monodon. Aquaculture., 261(4): 1447-1454. https://doi.org/10.1016/j.aquaculture.2006.08.044

Xue S. Y., Zhao F. Z., Fang J. G., 2012. Effects of temperature and salinity on hatching, survival and growth of amphipod crustacean (Eogammarus sinensis). Journal of Fisheries of China, 36(7): 1094-1101. 
Zhan Y.Y., Huang X.Y., Duan L.Z., 2013. Effects of ocean acidification on offshore marine life. Journal of Dalian University., 34(3): 79-84.

Zhang M.L., Zou J., Fang J.G., 2011. Effects of ocean acidification on calcification, respiration and energy metabolism of scallop Chlamys farreri. Progress in Fishery Sciences., 32(4): 48-54.

Zhou J.M., Li N., Wang H., Mu C.K., Wang C.L., 2020. Effects of salinity on the ions important and sodium - potassium ATPase in osmoregulation, cortisol, amino acids, digestive and immune enzymes in Scylla paramamosain during indoor overwintering. Aquaculture Research., 51:4173-4182. 